\title{
Trisomy 13 mosaicism syndrome with atypical plurimalformative phenotype
}

\author{
Albu C.. ${ }^{*}$, Albu D. ${ }^{2}$, Albu S. ${ }^{3}$ \\ DOI: https://doi.org/10.17511/ijmrr.2019.i06.19 \\ 1* Cristina-Crenguta Albu, Lecturer, Department of Genetics, University of Medicine and Pharmacy "Carol Davila", Bucharest, Romania. \\ 2 Dinu-Florin Albu, Associate Professor, Department of Obstetrics and Gynecology, University of Medicine and Pharmacy "Carol Davila", \\ Bucharest, Romania. \\ 3 Stefan-Dimitrie Albu, DMD, Alco San Medical Center, Bucharest, Romania.
}

Introduction: Orofacial clefts are important congenital malformations of the lip, palate, or both caused by complex genetic and environmental factors. Aims and Objectives: The present study aims to highlight the phenotypic heterogeneity of trisomy 13 mosaicism. Material and Methods: We present one clinical case of a 30-year-old, Caucasian woman who is pregnant for the first time. Techniques of work study: anamnesis, clinical examination, serological tests for Toxoplasmosis, Rubeola, CMV and Herpes, ultrasound examination at 20 weeks gestation with General Electric Echographe Voluson E10 BT18, amniocentesis, fetal chromosome analysis and genetic counseling. Results: Ultrasound examination showed a viable singleton fetus with intra-uterine growth restriction, oligohydramnios, bilateral cleft lip and cleft palate, hypoplastic nasal bone and bilateral polycystic kidneys. Amniocentesis was done, and the fetal chromosomal analysis revealed a fetus with 46, XY/47, XY, +13 mosaic karyotype. After a complex genetic counselling the parents opted, to terminate the pregnancy. The autopsy confirm the prenatal ultrasound diagnosis. Conclusion: Routine ultrasound examination during pregnancy and specific genetic testing are essential for the early prenatal detection of major structural fetal anomalies associated with rare genetic chromosome syndromes.

Keywords: Oligohydramnios, Cleft lip/palate, Polycystic kidneys, Ultrasound diagnosis, Trisomy 13 mosaicism, Prenatal testing, Genetic counseling

\section{Corresponding Author}

Cristina-Crenguta Albu, Lecturer, Department of Genetics, University of Medicine and Pharmacy "Carol Davila", Bucharest, Romania

Email: crenguta.albu@yahoo.com

\section{How to Cite this Article}

To Browse

Albu CC, Albu DF, Albu SD. Trisomy 13 mosaicism syndrome with atypical plurimalformative phenotype. Int J Med Res Rev. 2019;7(6):574-578.

Available From

https://ijmrr.medresearch.in/index.php/ijmrr/article/ view/1098

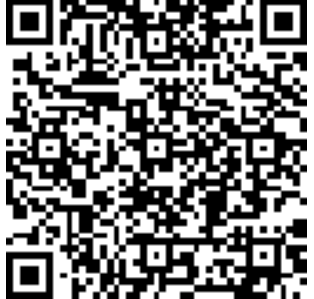

Manuscript Received 2019-10-14

Conflict of Interest No
Review Round 1 2019-10-24 Nil

(c) 2019 by Cristina-Crenguta Albu, Dinu-Florin Albu, Stefan-Dimitrie Albu and Published by Siddharth Health Research and Social Welfare Society. This is an Open Access article licensed under a Creative Commons Attribution 4.0 International License ttps://creativecommons.org/licenses/by/4.0/ unported [CC BY 4.0].

Accepted 2019-11-03

Note 


\section{Introduction}

Orofacial cleft, caused by the interaction of complex genetic factors and environmental, is one of the important congenital abnormalities which impacts negatively on the life of the individual and to a large extent affects the family $[1,2]$. Orofacial clefts represent all those defects involving the upper lip, with or without extension to the alveolar ridge or primary palate, and to the hard or secondary palate [3]. The incidence of facial cleft varied in geographical distribution because of ethnic and environmental differences [4]. In Romania, in 1997, children with orofacial clefts represented $2.18 \%$ from the total of all children institutionalized and the average rate of prevalence of live births with orofacial clefts was 3.7/year [5]. Cleft palate with or without cleft lip can occur isolated (70\% of cases), or as part of developmental syndromes that are the result of chromosomal abnormaties or teratogenic conditions [6-8]. According to Fogh and Anderson less than $40 \%$ of cases of cleft lip with or without cleft palate are genetic in origin transmitted through a male sex-linked recessive gene and less than $20 \%$ of isolated cleft palates are genetically determined [9]. Sometimes orofacial clefts are diagnosed by prenatal ultrasound, but there is no systematic screening for orofacial clefts [1]. Genetic counselling for this condition is complex. The frequency of orofacial clefts for another child is significantly dependent on the severity of the malformation and the presence of a positive family history of cleft $[10,11]$.

\section{Case Report}

We present a clinical case of a 30-year-old, Caucasian woman, pregnant for the first time, who was referred at 20 weeks' gestation in a private medical centre in Bucharest, Romania, for a routine prenatal ultrasound examination. The couple was non-consanguineous and clinically healthy. There was no family history of cleft lip, cleft palate, polycystic kidneys, genetic disorders or other congenital malformations.

The diagnostic methods used were: anamnesis, clinical examination, serological tests for Toxoplasmosis, Rubeola, CMV and Herpes, ultrasound examination at 20 weeks gestation, selective ultrasonography for detection of fetal abnormalities, 3D and 4D scan with General Electric Echographe Voluson E10 BT18, genetic amniocentesis, fetal chromosome analysis using
Amniocytes cultured from a sample of amniotic fluid, pre- and post-procedure genetic counseling [12]. Diagnostic ultrasound examination at 20 weeks' gestation revealed a single live fetus with: oligohydramnios (Amniotic Fluid Index, AFI = $67.00 \mathrm{~mm})$, (Figure 1), hypoplastic nasal bone (Nasal Bone Length, NBL = $2.26 \mathrm{~mm}$ ), (Figure 2), bilateral cleft lip and cleft palate (Figure 3), bilateral polycystic kidney (Figure 4) and intra-uterine growth restriction (Figure 5).

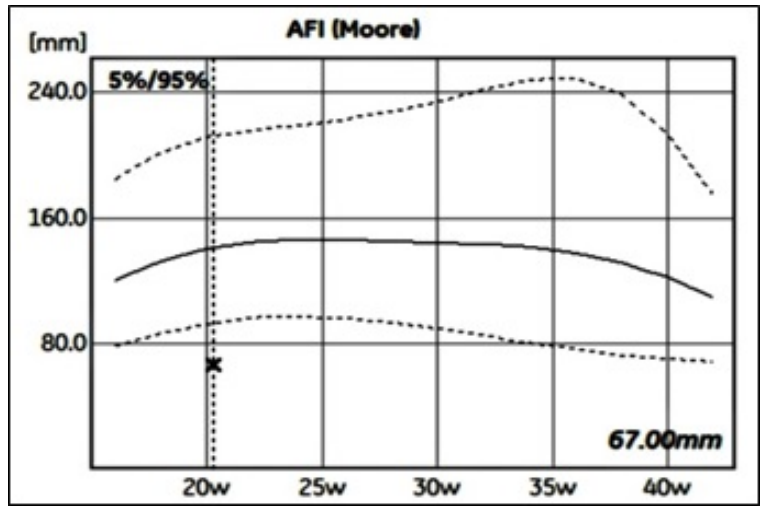

Fig-1: Obstetrics report: amniotic fluid index $(A F I=67.00 \mathrm{~mm})$. Oligohydramnios.

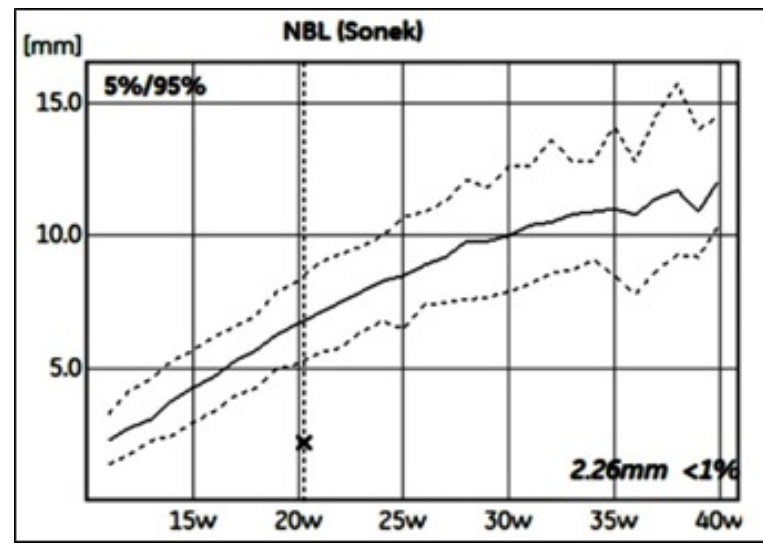

Fig-2: Obstetrics report: nasal bone length (NBL = $2.26 \mathrm{~mm}$ ). Hypoplastic nasal bone.

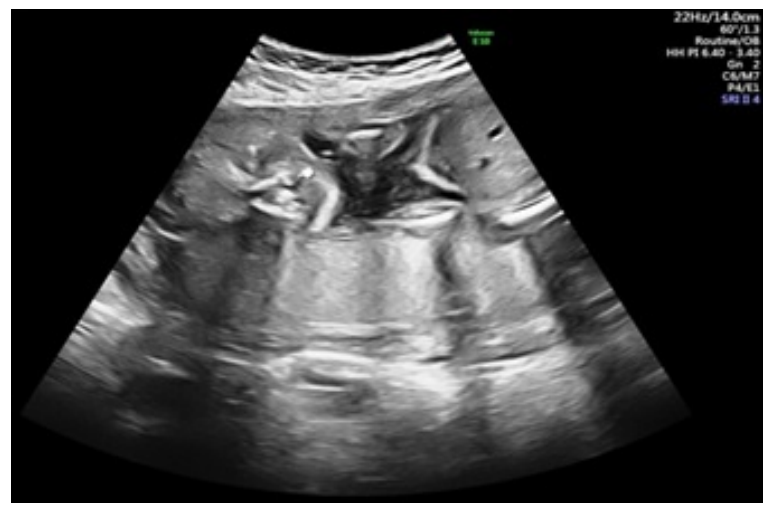


Fig-3: Ultrasound examination: Bilateral cleft lip and cleft palate.

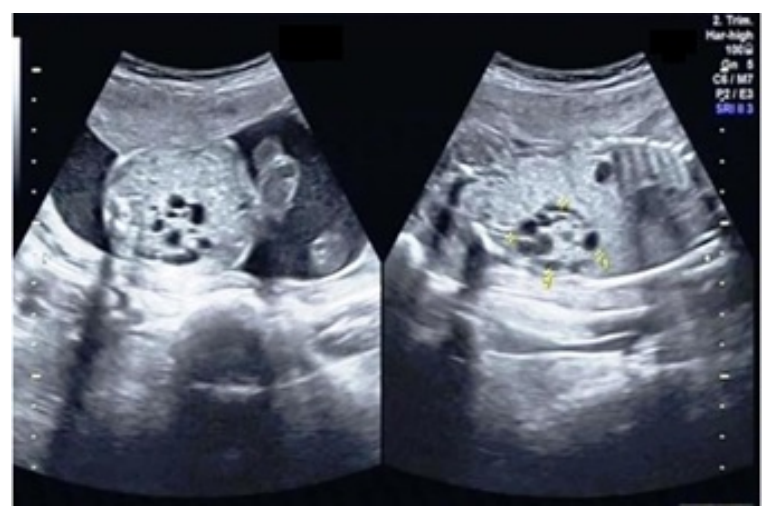

Fig-4: Ultrasound examination: polycystic kidney.

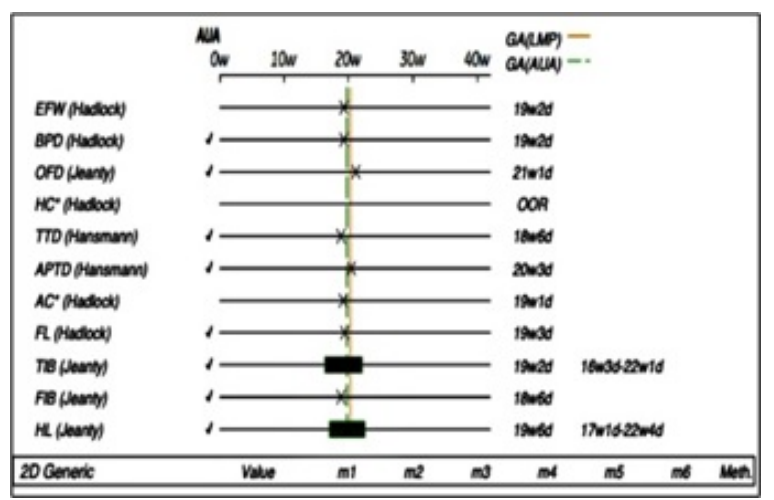

Fig-5: Obstetrics report: Intra-uterine growth restriction.

Genetic amniocentesis and the fetal chromosome analysis using amniocytes cultured from a sample of amniotic fluid revealed a karyotype of $46, X Y / 47, X Y,+13$ (Figure 6). Cytogenetic analysis demonstrated trisomy 13 mosaicism. The parental karyotypes were normal.

After the comprehensive prenatal testing the following diagnosis was established: Pregnancy 21 weeks in evolution. Trisomy 13 mosaicism $46, X Y / 47, X Y,+13$. Intra-uterine growth restriction. Oligohydramnios. Hypoplastic nasal bone. Bilateral cleft lip and cleft palate. Bilateral polycystic kidney. Estimated weight: $286 \mathrm{~g}$.

Following a difficult post-procedure genetic counseling the parents opted to terminate the pregnancy. Fetal pathology, detected prenatally by imagistic and cytogenetic methods was confirmed by fetal autopsy. At the moment, the mother are feeling well.

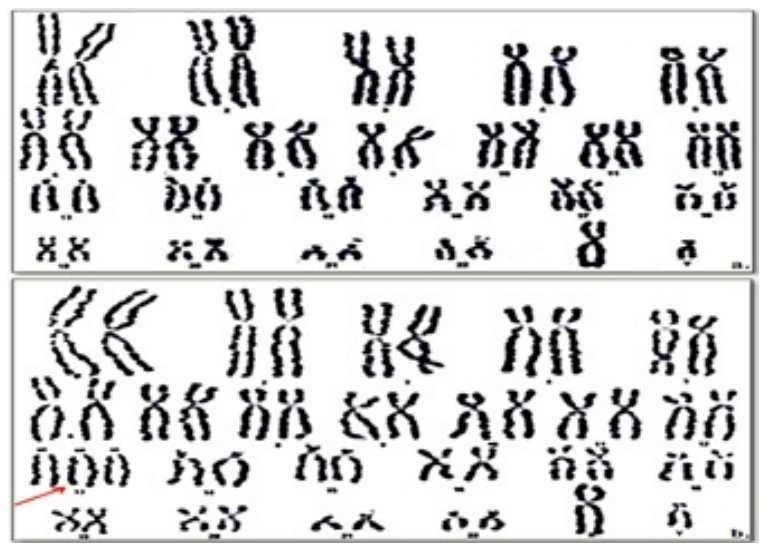

Fig-6: Fetal karyotype 46, $X Y / 47, X Y,+13$. Slide 1 (a) and Slide 3 (b) Specimen type: Amniotic fluid, 20 weeks of pregnancy.

\section{Discussion}

Cleft lip and cleft palate, important human congenital malformations with a complex multifactorial etiology, can occur as part of a syndrome involving multiple organs or as isolated clefts without other detectable defects [13]. Orofacial clefts require complex multidisciplinary treatment and are associated with elevated infant mortality and significant lifelong morbidity [14].

When occurring as part of a genetic syndrome, the complexity of management increases and has lifelong implications for these individuals, their families, and their health care providers [15].

Trisomy 13, a chromosomal alteration with an incidence of 1 in 10,000 to 20,000 births, can occur completely, partially or in mosaicism; the latter occurs when a percentage of cells are trisomic for chromosome 13, while the rest are euploid in an individual and corresponds to only $5 \%$ of all cases [16]. Trisomy 13 mosaicism occurs when two cell lines, one with a normal complement of chromosomes and the other with an additional chromosome 13 , are present in the same individual [17].

Mosaic trisomy 13 is very rare [18]. Constitutional chromosomal mosaicism is the result of post fertilization mitotic error, the mechanism of which is not fully understood [19]. Microsatellite analyses of trisomy 13 have indicated the high incidence of maternal meiotic origin and reduced recombination [20]. In our case report the karyotype of parents was normal which suggests that origin of abnormality was de-novo. 
While the clinical features associated with full trisomy 13 have been well characterized, the phenotype and clinical outcome associated with mosaic trisomy 13 are much less clear and poorly understood [21].

The phenotype of mosaic trisomy 13 varies widely; some patients may have the typical phenotype of trisomy 13 with neonatal death, while others may have few dysmorphic features and prolonged survival because the phenotype changes according to the distribution of the abnormal cells in specific tissues $[22,23]$.

There is no consensus about the typical phenotype in these cases [21]. In this study, we present a rare case of a fetus diagnosed prenatally in our clinic with trisomy 13 mosaicism who had multiple severe congenital malformations: bilateral cleft lip/palate and bilateral polycystic kidney, accompanied by oligohydramnios and intra-uterine growth restriction. The parents' decision to terminate increased with the severity of the genetic defect and the associated anomalies of the fetus [24]. The decision were mostly influenced by the genetic component. Counseling parents of a fetus with trisomy 13 mosaicism remains difficult because of the phenotypic variability associated with the condition [25].

\section{Conclusion}

Routine ultrasound examination during pregnancy and specific genetic testing are essential for the early prenatal detection of major structural fetal anomalies associated with rare genetic chromosome syndromes.

\section{Reference}

01. Agbenorku P. Orofacial clefts- a worldwide review of the problem. ISRN Plastic Surg.

2013. Doi: 10.5402/2013/348465 [Crossref]

02. Wehby GL, Murray JC. Folic acid and orofacial clefts- a review of the evidence. Oral Dis.

2010;16(1)11-19. doi: 10.1111/j.16010825.2009.01587.x [Crossref]

03. Gómez O, Puerto B. Cleft Lip and Palate, in Obstetric Imaging. Fetal Diagnosis and Care (2nd Ed).

2018. doi: 10.1016/C2014-0-00100-1 [Crossref]
04. Chang WJ, See LC, Lo LJ. Time trend of incidence rates of cleft lip/palate in Taiwan from 1994 to 2013. Biomed J.

2016;39(2)150-154. doi: 10.1016/j.bj.2015.10.003 [Crossref]

05. Zegan G, Lesner G. The characteristics of orofacial clefts in small communities. Rev Med Chir Soc Med Nat Iasi.

2012;116(2)605-610 [Crossref]

06. Kouskoura T, Fragou N, Alexiou M, John N, Sommer L, Graf D, et al. The genetic basis of craniofacial and dental abnormalities. Schweiz Monatsschr Zahnmed.

2011;121(7-8) 636-646 [Crossref]

07. Stanier P, Moore GE. Genetics of cleft lip and palate- syndromic genes contribute to the incidence of non-syndromic clefts. Hum Mol Genet.

2004;13(1)R73-R81. doi: 10.1093/hmg/ddh052 [Crossref]

08. Albu DF, Albu CC, Albu SD. Importance of ultrasound investigation in the early prenatal diagnosis of an Oral-Facial-Digital Syndrome Type I- a new case report. Int J Med Res Rev.

2016;4(1)118-121. doi: 10.17511/ijmrr.2016.i01.018 [Crossref]

09. Leslie EJ, Marazita ML. Genetics of cleft lip and cleft palate. Am J Med Genet C Semin Med Genet.

2013;163C(4)246-258. doi: 10.1002/ajmg.c.31381 [Crossref]

10. Tenconi RO, Clementi MA, Turolla LI. Theoretical recurrence risks for cleft lip derived from a population of consecutive newborns. J Med Genet.

1988;25(4)243-246. doi: 10.1136/jmg.25.4.243 [Crossref]

11. Kot M, Kruk-Jeromini J. Analysis of family incidence of cleft lip and/or palate. Med Sci Monit.

2007;13(5)CR231-C234 [Crossref]

12. Ion G, Albu CC, Albu SD, Albu DF. The benefits of prenatal testing associated with oral and maxillofacial pathology- new case report. EJBPS. 2017;4(4)670-673 [Crossref] 
13. Gritli-Linde A. The etiopathogenesis of cleft lip and cleft palate- usefulness and caveats of mouse models. Curr Top Dev Biol.

2008;84;37-138. doi: $10.1016 /$ S00702153(08)00602-9 [Crossref]

14. Jugessur A, Farlie PG, Kilpatrick N. The genetics of isolated orofacial clefts: from genotypes to subphenotypes. Oral Dis.

2009;15(7)437-453. doi: 10.1111/j.16010825.2009.01577.x [Crossref]

15. Hoffman-Andrews L, Tarnowski JM, Lee S, Hasegawa- Evans L, Lau HL, Meister JC, et al. Characteristics of Orofacial Clefting in Hawai'i. Hawaii J Health Soc Welf. 2019;78(8)258-261 [Crossref]

16. Cammarata-Scalisi $F$, Araque $D$, Ramírez $R$, Guaran L, Silva GD. Trisomy 13 mosaicism. Bol Med Hosp Infant Mex.

2019;76(5)246-250. doi: 10.24875/BMHIM. 1900 0003 [Crossref]

17. Griffith $C B$, Vance GH, Weaver DD. Phenotypic variability in trisomy 13 mosaicism- two new patients and literature review. Am J Med Genet A.

$2009 ; 149 A(6) 1346-1358$.

doi:

10.1002/ajmg.a.32883 [Crossref]

18. Aypar E, Yildirim MS, Sert A, Ciftci I, Odabas D. A girl with metopic synostosis and trisomy 13 mosaicism- case report and review of the literature. Am J Med Genet A.

2011;155A(3)638-641. doi: 10.1002/ajmg.a.33839 [Crossref]

19. Kalousek DK. Pathogenesis of chromosomal mosaicism and its effect on early human development. Am J Med Genet.

2000;91(1)39-45. doi: 10.1002/(sici)10968628(20000306)91:1<39: :aid-ajmg7>3.0.co;2-I

[Crossref]
20. Jinawath $\mathrm{N}$, Zambrano $\mathrm{R}$, Wohler $\mathrm{E}$, Palmquist MK, Hoover-Fong J, Hamosh A, et al. Mosaic trisomy 13- understanding origin using SNP array. J Med Genet.

2011;48(5)323-326. doi: 10.1136/jmg.2010.083931 [Crossref]

21. Eubanks SR, Kuller JA, Amjadi D, Powell CM. Prenatal diagnosis of mosaic trisomy 13- a case report. Prenat Diagn.

1998;18(9)971-974. doi: $10.1002 /(\mathrm{sici}) 1097-$ 0223(199809)18:9<971: :aid-pd380>3.0.co;2-p [Crossref]

22. Pachajoa H, Meza Escobar LE. Mosaic trisomy 13 and a sacral appendage. BMJ Case Rep.

2013. doi: 10.1136/bcr-2012-008150 [Crossref]

23. Delatycki M, Gardner RJ. Three cases of trisomy 13 mosaicism and a review of the literature. Clin Genet.

1997;51(6)403-407. doi: $10.1111 / \mathrm{j} .1399-$ 0004.1997.tb 02499.x [Crossref]

24. Pavlicek J, Gruszka T, Polanska S, Dolezalkova $E$, Matura D, Spacek R, et al. Parents' request for termination of pregnancy due to a congenital heart defect of the fetus in a country with liberal interruption laws. J Matern Fetal Neonatal Med.

2019;1-9. doi: 10.1080/14767058.2018.1564029 [Crossref]

25. Chen CP. Prenatal diagnosis and genetic counseling for mosaic trisomy 13. Taiwan J Obstet Gynecol. 2010;49(1)13-22. doi: 10.1016/S10284559(10)60003-4 [Crossref] 